\title{
Obim ispitivanja zavarenog spoja prema SRPS EN 13445-5
}

T ehnički zahtevi koji se odnose na projektovanje, izradu i ocenjivanje usaglašenosti opreme pod pritiskom i sklopova kod kojih je najveći dozvoljeni pritisak PS veći od 0,5 bar definisani su PED direktivom 2014/69/EU [1], Pravilnikom o tehničkim zahtevima za projektovanje, izradu i ocenjivanje usaglašenosti opreme pod pritiskom (Službeni glasnik RS, 87/2011) [2] i Pravilnikom o pregledima opreme pod pritiskom tokom veka upotrebe (Službeni glasnik RS, 87/2011) [3]. Sigurnost opreme pod pritiskom je predmet mnogih propisa za njeno projektovanje, izradu, kontrolu i eksploataciju [4].

\section{UVOD}

Projektovanje, ispitivanje, izrada i ocenjivanje uaglašenosti posuda pod pritiskom koje nisu izložene plamenu obuhvaćene su standardima SRPS EN 13445-1-7. Standard je dokument koji sadrži zahteve i smernice primenjive na konkretno okruženje koje je predmet standardizacije. Pored toga sadrži i pojašnjenja, uputstva ili definicije, bazirane na naučnim istraživanjima ili pravilima dobre prakse. Najbitnija karakteristika standarda, koja ga razlikuje od gore pomenutih propisa, normi ili zakona je ta što on NIJE OBAVEZAN. Onoga trenutka kada se propiše njegova obavezna primena od strane državnih institucija on iz standarda prelazi u tehnički propis ili normativ. Standardi iste grupe se razlikuju po godini izdanja. Novija izdanja sadrže najnovije pristupe prema iskustvenim analizama ili naučnim istraživanjima. Veoma je važna primena važećeg, odnosno najnovijeg standarda.

U ovom radu će biti prikazana i diskutovana razlika u izdanjima standarda SRPS EN 13445-5:2009 [5] i SRPS EN 13445-5:2015 [6], u pogledu ispitnih grupa materijala. Takođe, na primeru dve identično projektovane posude pod pritiskom ali od različitog materijala, biće prikazan uticaj ovih izmena na obim ispitivanja metodama bez razaranja.

Ispitivanja bez razaranja posuda pod pritiskom zavise od ispitne grupe prema kojoj je posuda projektovana. Postoje 4 grupe, a grupe od 1 do 3 su podeljene u dve podgrupe svaka. Prilikom projektovanja posude pod pritiskom, moraju se uzeti u obzir ispitne grupa. Ako materijal, maksimalna debljina, proces zavarivanja i temperaturni opseg ispunjavaju uslove, moguće je staviti posudu u višu grupu za koju je potreban manji stepen IBR ispitivanja. Ako je to slučaj, koeficijent zavarenog spoja mora da se prilagodi ispitnoj grupi [4].

\section{MATERIJALI I ISPITNE GRUPE}

Materijali koji se koriste za proizvodnju opreme pod pritiskom moraju odgovarati toj nameni u predviđenom veku trajanja ukoliko nisu predviđene zamene. Materijali za delove pod pritiskom moraju imati odgovarajuća svojstva za sve radne uslove koji se mogu predvideti i za sve uslove ispitivanja, oni moraju imati dovoljnu čvrstoću i žilavost [2].

Materijali moraju biti dovoljno hemijski otporni na fluide koje se nalaze u opremi pod pritiskom, ne smeju biti značajno podložni starenju, moraju odgovarati za predviđene postupke obrade i moraju se odabrati na način da ne dođe do neželjenih efekata kada se spajaju različiti materijali.

Ispitna grupa određuje dozvoljene materijale, maksimalnu debljinu, dozvoljene procese zavarivanja, radni temperaturni opseg, koeficijent zavarivanja i obim ispitivanja bez razaranja (NDT) zavarenih spojeva.

Grupa 1 ima najmanja ograničenja, ali zahteva najšire ispitivanje, dok grupa 4 ima najviše ograničenja, ali zahteva najmanje testiranja. U grupi 4 uopšteno nije potrebno ispitivanje bez razaranja, sa malim brojem izuzetaka. Prilikom projektovanja posude pod pritiskom, moraju se uzeti u obzir ispitne grupa. Ako je materijal, maksimalna debljina, proces zavarivanja i temperaturni opseg ispunjavaju uslove, može biti moguće staviti posudu u višu grupu za koju je potrebno manje IBR ispitivanja. Ako je to slučaj, koeficijent zavarenog spoja mora da se prilagodi ispitnoj grupi.

Ispitne grupe 1, 2 i 3 su podeljene u podgrupe 1a, 1b, 2a, 2b, 3a, $3 \mathrm{~b}$, sa ciljem da reflektuju osetljivost materijala na prsline.

Kod izračunavanja potrebne debljine određenih zavarenih komponenata (npr. cilindara, konusa i sfera), proračunske formule sadrže $\mathrm{z}$, koeficijent valjanosti za glavne zavarene spojeve komponente.

Primeri glavnih zavarenih spojeva su:

- uzdužni ili spiralni spojevi na cilindričnom omotaču;

- $\quad$ uzdužni spojevi na koničnom omotaču;

- $\quad$ bilo koji glavni spoj na sferičnom omotaču/poklopcu;

- glavni spojevi na ispupčenom poklopcu izrađenom od dve ili više ploča.

Za slučajeve normalnog radnog opterećenja, vrednost $\mathrm{z}$ je data $\mathrm{u}$ tabeli 1. Ona se odnosi na odgovarajuću ispitnu grupu glavnih zavarenih spojeva. Ispitne grupe su određene u SRPS EN 13445-5:2015, tačka 6.

Tabela 1. Koeficijent valjanosti zavarenog spoja i odgovarajuća ispitna grupa

\begin{tabular}{|c|c|c|c|}
\hline $\mathbf{z}$ & $\mathbf{1}$ & $\mathbf{0 , 8 5}$ & $\mathbf{0 , 7}$ \\
\hline Ispitna grupa & 1,2 & 3 & 4 \\
\hline
\end{tabular}


Tabela 2. Obim IBR prema standardima SRPS EN 13445-5:2015 i SRPS EN 13445-5:2009

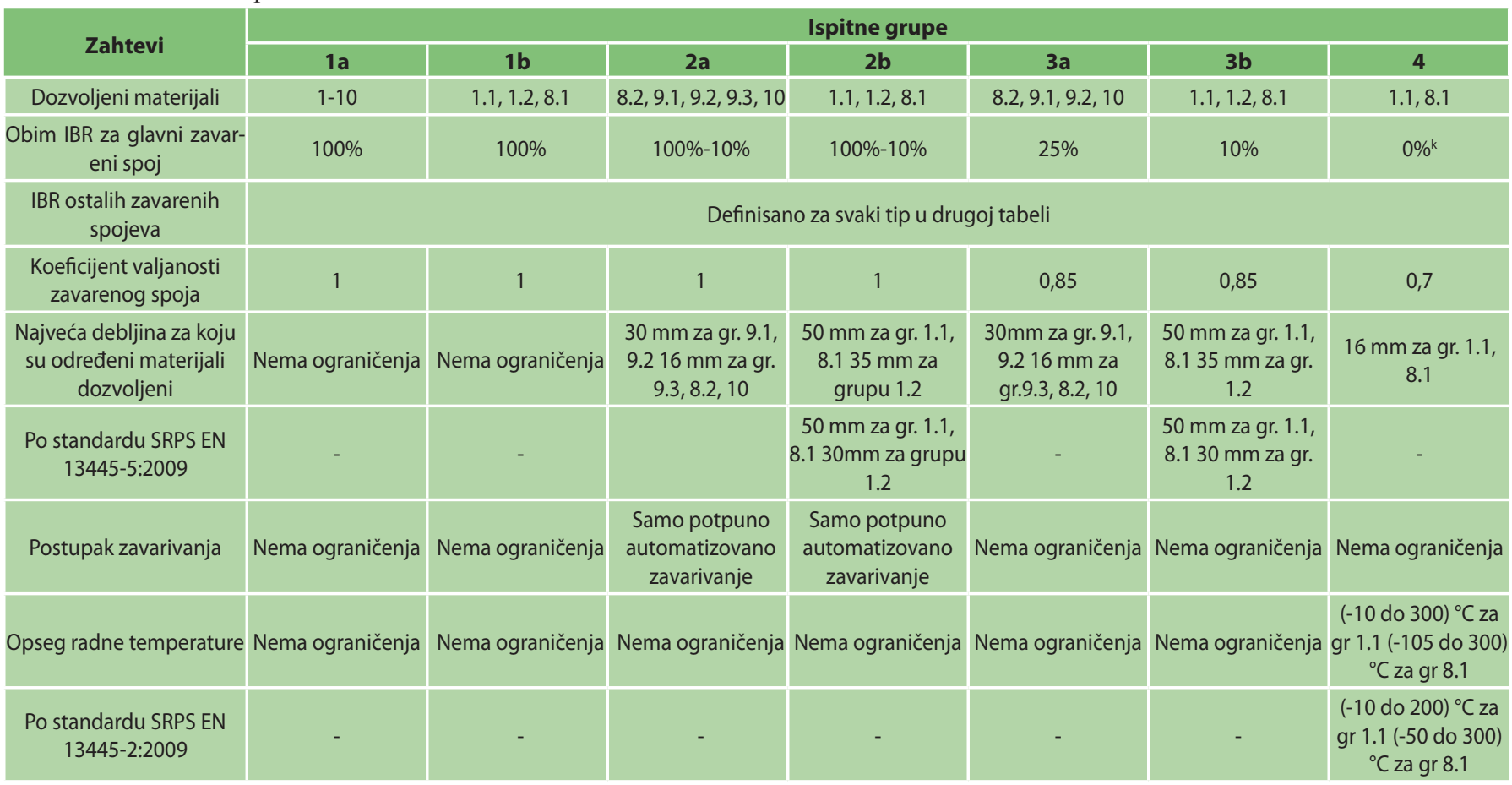

Za osnovni materijal, van glavnih zavarenih spojeva, je $\mathrm{z}=1$.

Za izuzetne i ispitne uslove se mora koristiti vrednost 1, bez obzira na ispitnu grupu.

Obim ispitivanja zavarenih spojeva metodama bez razaranja zavisi od ispitne grupe i od tipa zavarenog spoja.

Za opremu pod pritiskom, ispitivanja bez razaranja mora obaviti odgovarajuće kvalifikovano osoblje. Osoblje mora da bude sertifikovano prema ISO 9712. Za opremu pod pritiskom kategorije III i IV, osoblje mora biti odobreno od strane Imenovanog tela za nerastavljive spojeve.

U Tabeli 2 prikazane su ispitne grupe prema grupi materijala koji se koristi za izradu posude pod pritiskom prema standardu SRPS EN 13445-5:2015 i SRPS EN 13445-5:2009. Sivom bojom su označene razlike u obimu kontrole prema dva izdanja istog standarda. Iz Tabele 2 može da se primeti da standard SRPS EN 13445-5:2015 za grupe 2b i 3b materijal grupe 1,2 uzima veće maksimalne debljine, odnosno 35 $\mathrm{mm}$ u odnosu na $30 \mathrm{~mm}$ po starom standardu. Takođe, standard SRPS EN 13445-5:2015 za grupu 4 daje veći opseg radnih temperature, a za grupu 4 kod opreme sa spojem koničnog omotača za cilindrični bez prelaza uzima MT ili PT 100\%, što u prethodnom standardu nije razmatrano.

\section{ODREĐIVANJE OBIMA ISPITIVANJA BEZ RAZ- ARANJA}

Obim ispitivanja bez razaranja kod posuda pod pritiskom se određuje prema standardu SRPS EN 13445-5. U Tabeli 3 dat je obim IBR ispitivanja za ispitne grupe 1, 2 i 3, na sučeonom šavu sa punom penetracijom i za primene ispod opsega puzanja prema standardima SRPS EN 13445-5: 2015 i SRPS EN 13445-5: 2009, a sivom bojom je označena razlika ovih izdanja. U Tabeli 4 prikazane su ispitne podgrupe $1 \mathrm{c}$ i $3 \mathrm{c}$ na sučeonom šavu sa punom penetracijom koje se primenjuju za puzanje [4].

Po pravilu, obim ispitivanja bez razaranja, koji se daje kao procentualna vrednost, mora da bude u skladu sa tabelom 2 koja pokriva samo procese navedene u EN 13445-4: 2014. Ovaj procenat odražava stepen ispitivanja bez razaranja ukupne dužine zavarenog spoja i uzima u obzir ispitnu grupu i tip zavarenog spoja. Za posude projektovane eksperimentalnim metodama, potreban obim ispitivanja bez razaranja zavarenih spojeva se određuje prema pravilima datim u tabeli 3 .

Tabela 3 važi za sve spojeve, osim za longitudinalne glavne spojeve:

- $\quad$ u jednom prolazu sa samo jedne strane ;

- $\quad$ spojevi različitih materijala ili različitog dodatnog materijala.

Za ispitnu grupu 2, procenat IBR prikazan u tabeli 3 je dat sa dva podatka (npr 100\% - 10\%). Prva vrednost se odnosi na početni stepen ispitivanja, a druga, manja vrednost se primenjuje za zadovoljavajuće iskustvo.

Standard SRPS EN 13445-5:2009 prepoznaje samo oznaku „NA“ koja znači „tip zavarenog spoja nije dozvoljen“, dok standard SRPS EN 13445-5:2015 sem oznake „NA“ koja sada znači “ispitivanje nije primenljivo” uvodi i oznaku „NP“ koja znači “tip zavarenog spoja nije dozvoljen”. Izmene u ,novom“ standardu se odnose uglavnom na MT/PT metode, odnosno površinska ispitivanja i donekle na UT/ RT metode, odnosno zapreminska ispitivanja.

Interesantno je da je obim ispitivanja IBR metodama za obimni šav na omotaču uključujući spoj između omotača i nehemisferičnog danca (tip zavarenog spoja 2a) značajno smanjen u „,novom“ izdanju 
standarda, a za ispitne grupe 1a i 3a čak sa $100 \%$ na 25\%! Može da se pretpostavi da je analizom rezultata u razmaku od 5 i više godina došlo do zaključka da ovaj obim kontrole daje zadovoljavajuće rezultate u pogledu bebednosti ljudi i okoline.

Pojedini tipovi zavarenog spoja određene ispitne grupe su $\mathrm{u}$ starom standardu tretirani sa $100 \%$ kontrole, dok u novom standardu su označeni kao „NA“, odnosno “ispitivanje nije primenljivo”- Pretpostavlja se da dosadašnji rezultati nisu davali pouzdane zaključke o bezbednosti i sigurnosti zavarenog spoja.

Takođe, u standardu SRPS EN 13445-5:2015 minimalne debljine kod pojedinih ispitivanja su povećane sa 30 na $35 \mathrm{~mm}$.

Tabela 3. Obim IBR kontrole u standardima SRPS EN13445-5:2015 i SRPS EN 13445-5:2009. Podebljano i u kurzivu je označena razlika između dva standarda

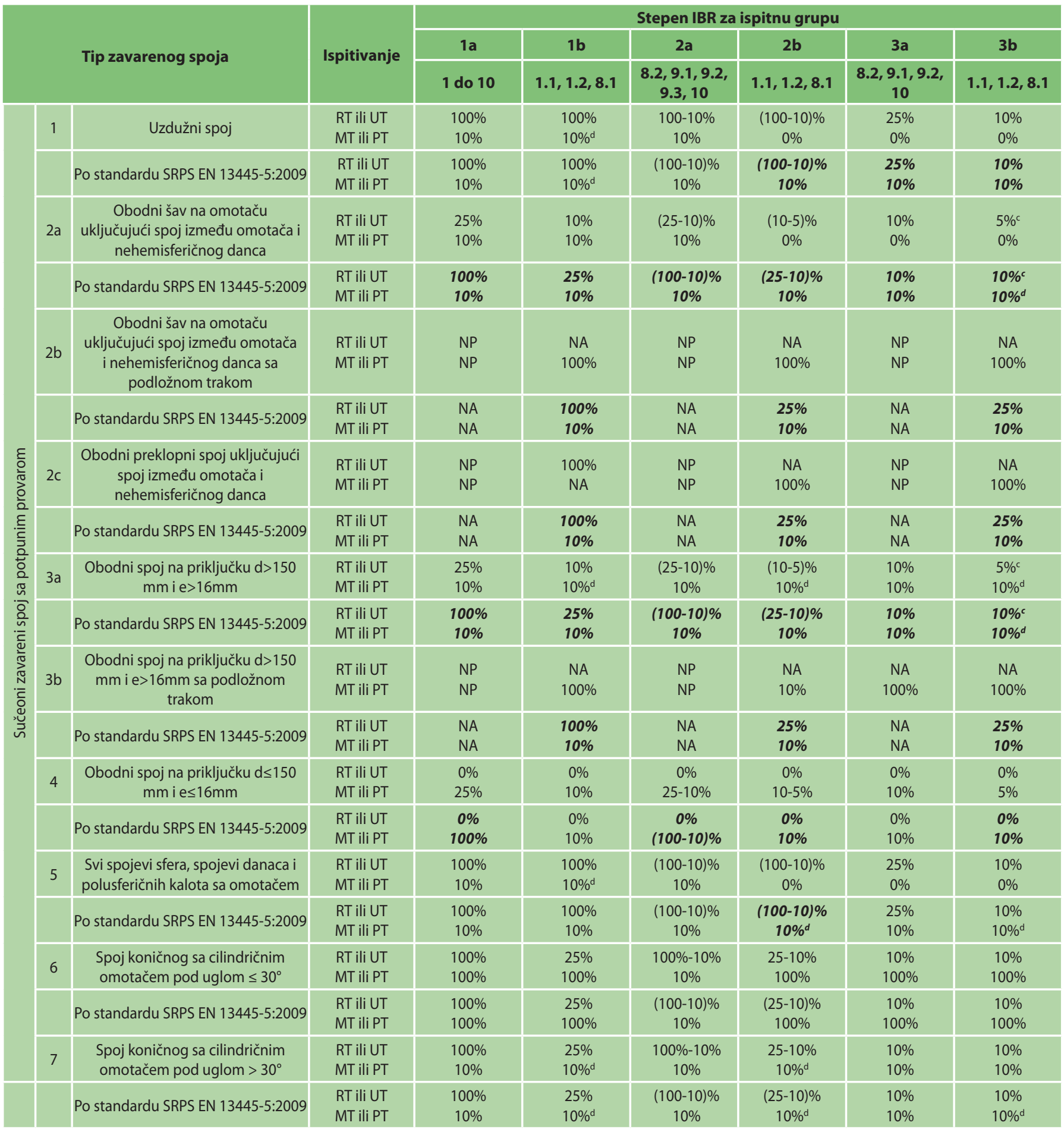


Tabela 4. Stepen IBR za ispitne grupe 1c i 3c na sučeonom zavarenom spoju punom penetracijom

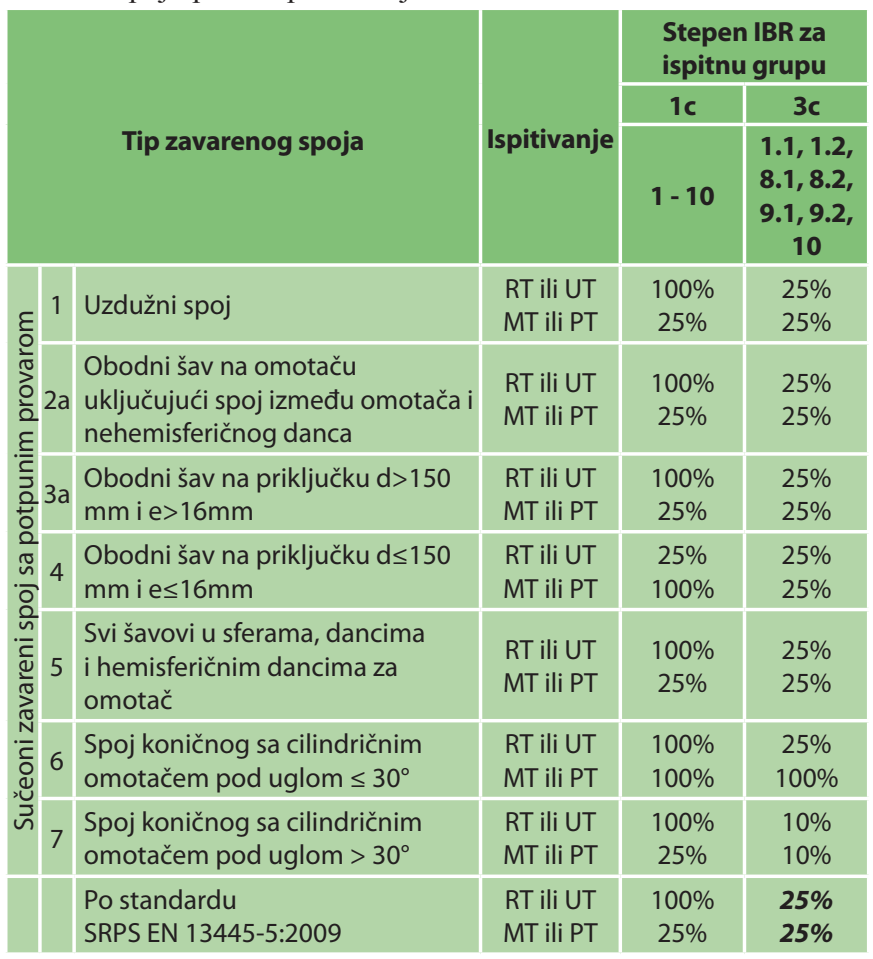

Vizuelni pregled obavlja se na svim šavovima. Ispitivanje bez razaranja zavarenih spojeva za završno prihvatanje će zavisiti od ispitne grupe spoja.

Nivo kvaliteta mora biti nivo C prema standardu EN ISO 5817: 2014.

\section{PRIMER ODREĐIVANJA OBIMA ISPITIVANJA BEZ RAZARANJA PREMA STANDARDIMA SRPS EN 13345-5:2009 I SRPS EN 13445-5:2015}

Na slici 1 [7] je dat šematski prikaz posude pod pritiskom - rezervoara za vazduh. posuda nije namenjena za serijsku proizvodnju i nema cikličnih opterećenja. Radni pritisak je 40 bar, prečnik 2000 $\mathrm{mm}$, radna temperatura $40^{\circ} \mathrm{C}$ i svi ugaoni šavovi su sa punom penetracijom. Koeficijent zavarenog spoja je 0,85 , svi ugaoni šavovi su sa punom penetracijom, radni pritisak 40 bar.

Radi bolje ilustracije razmatrane su dve vrste materijala: P295GH i X3CrNiMoBN17-13-3.

Za materijal P295GH (1.0481) usvojene su sledeće vrednosti: c1 $=0,3 \mathrm{~mm}-$ dodatak na negativnu toleranciju debljine lima, $\mathrm{C} 2=1,0$ $\mathrm{mm}$ - Dodatak na koroziju i habanje, $\mathrm{Z}=0,85$ - usvojeni koeficijent slabljenja zavarenog spoja. Izračunata vrednost debljine zida je e = $25,56 \mathrm{~mm}$ pa se usvaja $26 \mathrm{~mm}$.

Za materijal X3CrNiMoBN 17-13-3 (1-4910) usvojene su sledeće vrednosti : $\mathrm{c} 1=0,3 \mathrm{~mm}$ - dodatak na negativnu toleranciju debljine lima, $\mathrm{C} 2=0,0 \mathrm{~mm}$ - Dodatak na koroziju i habanje, $\mathrm{Z}=0,85$ - usvojeni koeficijent slabljenja zavarenog spoja, e = 23,56 $\mathrm{mm}$ - potrebna debljina zida. opt ćemo usvojiti $26 \mathrm{~mm}$ za debljinu zida.

Na posudi se nalazi revizioni otvor 1 (prečnik 600mm, debljina zida $26 \mathrm{~mm}$ ), priključci istog tipa 2-6 (prečnik $400 \mathrm{~mm}$,debljina 20 $\mathrm{mm}$ ) i priključak 7 (prečnik $600 \mathrm{~mm}$, debljina $26 \mathrm{~mm}$ ).

Dužina obimnog spoja za obe posude je $6380 \mathrm{~mm}$.

Prvo je potrebno odrediti grupu materijala. Prema standardu SRPS EN 13445-2:2015 [8] i Tabeli E.2-1 osnovni materijal P295GH pripada grupi 1.2 , a materijal X3CrNiMoBN17-13-3 pripada grupi 8.2 .

Kada smo odredili grupu materijala iz Tabele 3 određujemo ispitnu grupu (preuzeto iz iz standarda SRPS EN 13445-5:2015). Uzimajući u obzir da je koeficijent zavarenog spoja 0,85, kao i da je debljina zida $26 \mathrm{~mm}$, možemo da uzmemo nekoliko ispitnih grupa. Prema Tabeli 3 za materijal P295GH, odnosno grupu materijala 1,2 možemo da usvojimo ispitne grupe 1a,1b, 2b i 3b. Grupe 1a i 1b prema Tabeli 4 zahtevaju 100\% ultrazvučne ili radiografske kontrole. Grupa 2 b takođe zahteva 100\% kontrole za početni uzorak, dok procenat može da se smanji uz zadovoljavajuće iskustvo. Međutim, pretpostavka je da je ovo pojedinačna proizvodnja i da je ovo prvi primerak. Ispitna grupa $3 \mathrm{~b}$ zahteva svega $10 \%$ obima kontrole za IBR metode. S obzirom da proizvođač teži što manjim troškovima, odlučujemo se za minimum troškova i opredeljujemo se za grupu $3 \mathrm{~b}$.

Analogno, za materijal X3CrNiMoBN17-13-3, odnosno grupu 8.2, možemo da usvojimo grupe 1a, 2a ili 3a, i usvajamo 3 a.

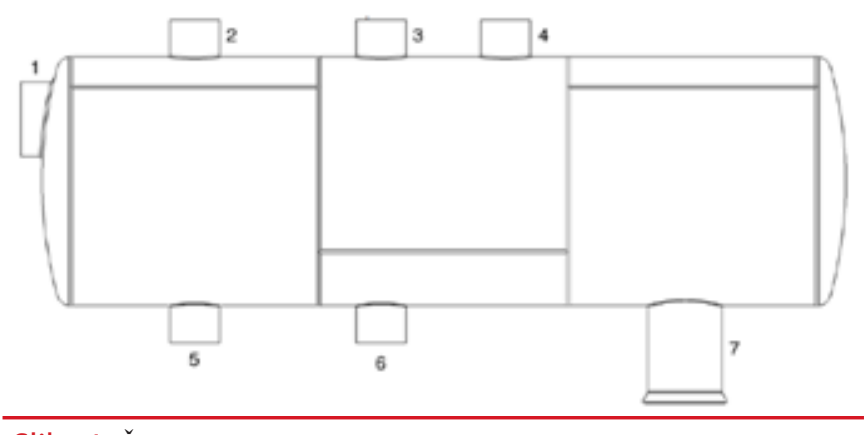

Slika 1: Šematski prikaz posude pod pritiskom [7]

Pošto smo odredili ispitnu grupu, potrebno je preciznije odrediti obim kontrole za pojedine zavarene spojeve (Tabela 4; SRPS EN 13445-5:2015). U slučaju manje od 100\% kontrole, određuju se obim i mesto ispitivanja na svim presečnim uzdužnim i obimnim šavovima. Minimalna dužina ispitivanja treba da bude $200 \mathrm{~mm}$.

Dužina uzdužnog spoja je $2000 \mathrm{~mm}$ (na posudi postoje tri uzdužna spoja). Obim ispitivanja ultrazvučne ili radiografske metode je $10 \%$, odnosno $200 \mathrm{~mm}$ zone ispitivanja. Prema standardu SRPS EN 13445-5:2015 i Tabeli 4 za grupu 3b nije potrebna površinska kontrola uzdužnog spoja. Prema standardu SRPS EN 13445-5:2009, površinske kontrole, magnetnim česticama ili penetrantima, su bile obavezne u obimu od $10 \%$ ali samo za materijale preko $30 \mathrm{~mm}$ debljine. Za obodni šav potreban obim UT ili RT je 5\%, što čini 314 mm prema standardu SRPS EN 13445-5:2015, dok se MT ili PT ne zahteva. Ovde postoji razlika između "starog" standarda SRPS EN 13445-5:2009, gde je zahtevani obim UT/RT kontrole iznosio 10\%, što bi u ovom slučaju iznosilo $628 \mathrm{~mm}$.

Analogno za materijal X3CrNiMoBN17-13-3, odnosno grupu 8,2 potreban obim ispitivanja uzdužnog šava UT/RT metodama je $25 \%$, 
odnosno $500 \mathrm{~mm}$, dok je obim ispitivanja MT/PT metodama $0 \%$ prema standardu SRPS EN 13445-5:2015. Ovde se obim ispitivanja razlikuje od prethodnog izdanja, kada je iznosio najmanje 10\%, odnosno $200 \mathrm{~mm}$ u konkretnom slučaju. Za obodne šavove obim UT/RT iznosi $10 \%$, odnosno $628 \mathrm{~mm}$. Ovde je takođe, uočljiva razlika u odnosu na prethodno izdanje kod MT/PT ispitivanja; po novom standardu ispitivanje nije neophodno, dok je po starom neophodno najmanje $10 \%$, odnosno $628 \mathrm{~mm}$.

Da bi se odredio obim ispitivanja bez razaranja priključaka na posudi (sučeoni spoj) broj priključaka zavarenih sučeono sa potpunim provarom se grupiše na sledeći način:

1. za $100 \%$ IBR: veličina grupe je 1(ispituje se svaki priključak pojedinačno) ;

2. za $25 \%$ IBR: veličina grupe je 4 (ispituje se svaki četvrti priključak);

3. za $10 \%$ IBR: veličina grupe je 10 (ispituje se svaki deseti priključak).

S obzirom da prikazani sud sadrži 5 priključaka istog tipa i da je obim kontrole $10 \%$ sledi da je potrebno ispitiati jedan priključak $100 \%$. Priključak 7 mora da bude posebno razmatran i predstavlja posebnu grupu, mora da bude kompletno ispitan. Isto važi i za revizioni otvor.

Analogno, za materijal X3CrNiMoBN17-13-3, odnosno grupu 8,2 , obim ispitivanja UT/RT metodom iznosi $10 \%$, pa važi sve navedeno kao i za prethodno razmatrani materijal.

Kompletan obim IBR kontrole za posudu od materijala P295GH prema SRPS EN 13445-5:2015 je sledeći:

- $600 \mathrm{~mm}$ uzdužnog spoja,

- $1256 \mathrm{~mm}$ za obimne spojeve,

- $1200 \mathrm{~mm}$ za priključke tipa 2 do 6 ,

- $1800 \mathrm{~mm}$ priključak $7 \mathrm{i}$

- $1800 \mathrm{~mm}$ priključak 1 .

Tabela 5. Obim IBR kontrole izražen u mm za prikazanu posudu u odnosu na odabrani materijal i prema standardima SRPS EN 13445-5:2015 i SRPS EN 13445-5:2009

\begin{tabular}{|l|c|c|c|c|}
\hline $\begin{array}{c}\text { Ispitivani } \\
\text { spoj }\end{array}$ & $\begin{array}{c}\text { materijal } \\
\text { P295GH SRPS } \\
\text { EN 13445-5: } \\
\mathbf{2 0 1 4}\end{array}$ & $\begin{array}{c}\text { materijal } \\
\text { P295GH SRPS } \\
\text { EN 13445- } \\
\mathbf{5 : 2 0 0 9}\end{array}$ & $\begin{array}{c}\text { Materijal } \\
\text { X3CrNi } \\
\text { MoBN17-13-3 } \\
\text { SRPS EN 13445- } \\
\text { 5:2014 }\end{array}$ & $\begin{array}{c}\text { materijal } \\
\text { X3CrNi } \\
\text { MoBN17-13-3 }\end{array}$ \\
\hline $\begin{array}{l}\text { Uzdužni spoj } \\
\text { (mm) }\end{array}$ & 600 & 600 & 1500 \\
\hline $\begin{array}{l}\text { obodni spoj } \\
\text { (mm) }\end{array}$ & 1256 & 2512 & 2512 & 600 \\
\hline $\begin{array}{l}\text { priključci tipa } \\
\text { 2-6 (mm) }\end{array}$ & 1256 & 1256 & 1256 & 1256 \\
\hline $\begin{array}{l}\text { priključak 1 } \\
\text { (mm) }\end{array}$ & 1884 & 1884 & 1884 & 1884 \\
\hline $\begin{array}{l}\text { priključak 7 } \\
\text { (mm) }\end{array}$ & 1884 & 1884 & 1884 & 1884 \\
\hline
\end{tabular}

\section{$5 \quad$ ZAKLJUČAK}

U radu je dat prikaz međusobnog uticaja izbora materijala, ispitne grupe materijala, koeficijenta zavarenog spoja i obima ispitivanja bez razaranja posuda pod pritiskom.
Obim ispitivanja bez razaranja kod posuda pod pritiskom analiziran je kroz grupu standarda SRPS EN 13345, sa osvrtom na uočene bitne razlike u sva poslednja izdanja standarda SRPS EN 13445-5.

Kroz primer određivanja grupe materijala, koeficijenta zavarenog spoja, ispitne grupe i na kraju obima IBR kontrole prikan je uticaj izmene u obimu kontrole u standardu SRPS EN 13445-5:2015 i SRPS EN 13445-5:2009.

ZAHVALNOST. Ovaj rad je proistekao iz projekta Ministarstva prosvete, nauke i tehnološkog razvoja Republike Srbije TR 35040.

\section{LITERATURA}

[1] ***, Direktiva 2014/68/EU Evropskog saveta i veća (Službeni list Evropske Unije), 2014.

[2] ***, Pravilnik o tehničkim zahtevima za projektovanje, izradu $i$ ocenjivanje usaglašenosti opreme pod pritiskom, "Sl. glasnik RS", br. $87 / 2011$

[3] ***, Pravilnik o pregledima opreme pod pritiskom tokom veka upotrebe, ,Sl. gl RS”, br. 87/2011

[4] Petronić, S., Uticaj ispitnih grupa na stepen ispitivanja bez razaranja kod opreme pod pritiskom, Međunarodno savetovanje "IBR 16", Zavod za zavarivanje, Subotica, Srbija, 2016.

[5] ***, SRPS EN 13445-5:2009, Posude pod pritiskom koje nisu izložene plamenu - Deo 5, ISS, 2009.

[6] ***, SRPS EN 13445-5:2015, Posude pod pritiskom koje nisu izložene plamenu - Deo 5, ISS, 2015.

[7] Boehm, P., EN 13445-Unfired Pressure Vessels - A Useful Standard for Europe?, Athens: ATINER'S Conference Paper Series, No: IND2014-1039, 2014.

[8] ***, SRPS EN 13445-2:2015, Posude pod pritiskom koje nisu izložene plamenu - Deo 2, ISS, 2015.

\section{Autori}

\section{dr Sanja PETRONIĆ}

Inovacioni centar Mašinskog fakulteta u Beogradu, d.o.0., Kraljice Marije 16, Beograd spetronic@mas.bg.ac.rs

dr Radomir JOVIČIĆ Inovacioni centar Mašinskog fakulteta u Beogradu, d.o.o.,

Kraljice Marije 16, Beograd djovicic@mas.bg.ac.rs

dr Olivera ERIĆ-CEKIĆ Inovacioni centar Mašinskog fakulteta u Beogradu, d.o.o.,

Kraljice Marije 16, Beograd oericcekic@mas.bg.ac.rs

Dimitrije MALJEVIĆ

Univerzitet u Beogradu - Mašinski fakultet,

Kraljice Marije 16, Beograd

dimitrije.maljevic@gmail.com 